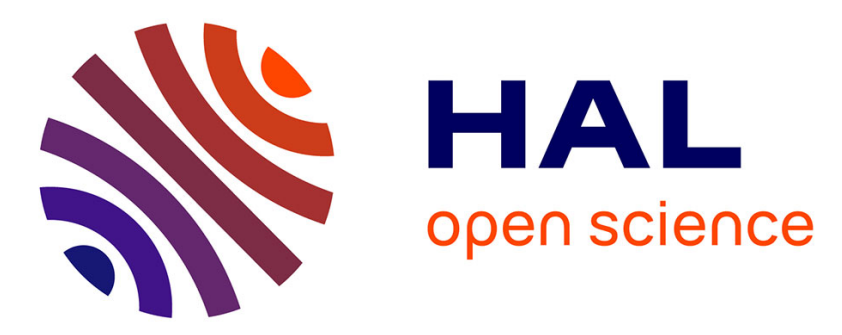

\title{
Imperfect competition, technical progress and capital accumulation
}

\author{
Biancamaria d'Onofrio, Bertrand Wigniolle
}

\section{To cite this version:}

Biancamaria d'Onofrio, Bertrand Wigniolle. Imperfect competition, technical progress and capital accumulation. International Journal of Economic Theory, 2010, 6 (4), pp.355-366. 10.1111/j.17427363.2010.00140.x . halshs-00185321v2

\section{HAL Id: halshs-00185321 \\ https://shs.hal.science/halshs-00185321v2}

Submitted on 30 Mar 2012

HAL is a multi-disciplinary open access archive for the deposit and dissemination of scientific research documents, whether they are published or not. The documents may come from teaching and research institutions in France or abroad, or from public or private research centers.
L'archive ouverte pluridisciplinaire HAL, est destinée au dépôt et à la diffusion de documents scientifiques de niveau recherche, publiés ou non, émanant des établissements d'enseignement et de recherche français ou étrangers, des laboratoires publics ou privés. 


\title{
Imperfect competition, technical progress and capital accumulation*
}

\author{
Biancamaria d'Onofrio ${ }^{\dagger}$ \\ Bertrand Wigniolle \\ Address for editorial correspondence: \\ Bertrand Wigniolle, \\ C.E.S., Maison des Sciences Economiques, \\ 106-112, boulevard de l'hôpital, \\ 75647 Paris Cedex 13, France. \\ Tel: +33 (0)1 440781 98. Fax: +33 (0)1 44078231 . \\ Email: wignioll@univ-paris1.fr.
}

${ }^{*}$ This research was started during a stay by Bertrand Wigniolle in Roma. The invitation of the Università di Roma "La Sapienza" and of the Banca d'Italia is gratefully acknowledged. Bertrand Wigniolle also thanks ANR (project ANR-05-BLAN-0347-01) for financial support. The authors thank participants of the GED seminar (Centre d'Economie de la Sorbonne) for their helpful comments, and Nicholas Sowels for a careful reading. They are also grateful to an anonymous referee for many corrections and improvements.

†Dipartimento di Matematica, Universita di Roma, "La Sapienza", Piazzale Aldo Moro 2, 00185 Rome, Italy. Tel: +39 06 49913253. Email: biancamaria.donofrio@uniroma1.it

${ }^{\ddagger}$ Paris School of Economics, University of Paris I. Address: C.E.S., Maison des Sciences Economiques, 106-112, boulevard de l'hôpital, 75647 Paris Cedex 13, France. Tel: +33 (0)1 4407 81 98. Email: wignioll@univ-paris1.fr. 


\begin{abstract}
This paper constructs a dynamic equilibrium growth model, in which some firms act as monopsonies on the labor market. The framework is an OLG growth model with altruistic agents. Two types of firms exist, competitive and non-competitive, the latter being endowed with a more productive technology. They behave strategically on the labor market, in taking into account the impact of their demand for labor on the equilibrium wage and on their profit. In this framework, the impact of a technical progress on capital accumulation can be positive or negative, depending on its effect on monopsony power.
\end{abstract}

JEL classification: D43, D9, O3

Keywords: imperfect competition, capital accumulation, technical progress. 


\section{Introduction}

This paper constructs a dynamic equilibrium growth model, in which some firms act as monopsonies on the labor market. Bhaskar, Manning and To (2002) give many arguments in favor of the assumption of oligopsony competition in labor market. They review the main theoretical arguments that all use static frameworks. Introducing monopsony power in a dynamic growth model allows to study its impact on capital accumulation, and to reveal paradoxical effects: for instance, a technical progress may decrease capital accumulation if it leads to distortions due to imperfect competition.

We consider an economy populated by firms that differ by their productivity. Firms with the lowest productivity are competitive as their technology is freely available. A few number of firms hold an exclusive technology with a higher productivity, and have a non-competitive behavior. Indeed, if all firms behaved competitively, only the firm endowed with the most productive technology would be active in equilibrium. But the assumption of perfect competition would become meaningless with only one firm on the market.

The most productive firms realize that they hold some market power on the labor market, and take into account the impact of their demand for labor on wages. We thus obtain an equilibrium with strategic (oligopsonic) behaviors in the labor market. This type of behavior tends to reduce the equilibrium wage and to increase the gross interest rate. In a growth model, capital accumulation depends on savings rates on capital income and wage income. The non-competitive behavior of firms will then imply a change in capital accumulation that will depend on these two savings rates.

In this framework is studied the impact on capital accumulation of a technical progress. In a competitive economy, this impact is always positive. In a noncompetitive model, the impact can be positive or negative, depending on its effect on monopsony power. Taking as fixed all productivities, we study in details the impact of a technical progress that benefits to a non-competitive firm and a technical progress affecting the competitive sector. Finally, in a last part a simple example is studied in which productivities may vary across time through innovations. At each period, one firm may benefit from a random innovation that increases its productivity by some given factor. The innovator has an exclusive use of its technology during one period, but it becomes freely available after. In this context, the occurrence of an innovation can have a negative short run impact on the growth rate, because imperfect competition decreases the equilibrium wage. But, after one period, the effect is positive as the technology is available for the competitive sector.

Little work has been done that introduces monopsony into a dynamic general equilibrium models, in spite of the importance of monopsony in the labor market. On the other hand, some authors have focused on non-competitive behaviors on the capital market in dynamic general equilibrium models, mainly Sorger (2002) and Becker (2003). In these models, firms are perfectly competitive and consumers behave non-competitively in the capital market. A long run equilibrium exists in which consumers endowed with different rates of time preference hold positive amounts of 
capital.

The imperfect competition mechanism that we introduce in this paper can also be viewed in the line of Cournot-Walras equilibrium (Gabszewicz and Vial 1972; Codognato and Gabszewicz 1993). Recent papers have used this concept in various frameworks. Belan, Michel and Wigniolle (2002) show that it can be fruitful to interpret pension funds behavior. Belan, Michel and Wigniolle (2005) wonder if imperfect competition can foster capital accumulation in a developing economy.

The paper is organized as follows. Section 2 presents the game played by noncompetitive firms. Section 3 studies households' behavior. Section 4 presents the intertemporal long run equilibrium. Section 5 analyses the impact of an exogenous technical change on capital accumulation. Section 6 concludes. The most complex proofs are available in the appendix of the working paper (d'Onofrio and Wigniolle 2006), and also upon request.

\section{The productive sector}

First we define the equilibrium concept. Second, the existence of an equilibrium is proved. Third, the impact of imperfect competition on equilibrium prices is studied.

\subsection{Definition of the equilibrium concept}

We consider an imperfect competition concept in the line of the Cournot-Walras equilibrium. At each period $t$ occurs a game consisting of three steps. In a first step, households allocate their savings between the different firms, arbitrating between the different capital returns. At the second step, the non-competitive firms choose their labor demand (their strategic variable). In the third step, an equilibrium occurs on the labor market that determines the equilibrium wage.

We now make precise the assumptions regarding the productive sector.

Firms employ capital and labor. Capital depreciates fully in one period. There exist two types of firms: competitive and non-competitive. Competitive firms have the same Cobb-Douglas technology given by:

$$
F\left(K_{0, t}, L_{0, t}\right)=A_{0} K_{0, t}^{\alpha} L_{0, t}^{1-\alpha} .
$$

Without loss of generality, it is possible to consider only one competitive firm, and we denote by $K_{0, t}$ and $L_{0, t}$ its amounts of capital and labor.

There exist $m$ non-competitive firms respectively endowed with Cobb-Douglas production technologies given by:

$$
\text { for } i=1, \ldots m, A_{i} K_{i, t}^{\alpha} L_{i, t}^{1-\alpha} \text {. }
$$

We assume the following inequalities: $A_{0}<A_{1}<\ldots .<A_{m}$. The lowest productivity corresponds to a basic technology which is freely available, and firms using this technology have a competitive behavior as they are numerous ${ }^{1}$. A few number of

\footnotetext{
${ }^{1}$ As usual, we fictitiously consider one firm in the competitive sector as the aggregate equilibrium of the competitive sector is independent of the number of firms.
} 
firms benefit from a higher productivity that may result from a past innovation. As each of them has an exclusive use of its own technology, it is natural to assume that they have non-competitive behaviors. We will assume along the first part of the paper that this production structure is identical at all periods.

At the beginning of period $t$, the total amount of capital $K_{t}$ is allocated by households among the different firms. This capital stock results from period $t-1$ savings behavior and for the moment, $K_{t}$ is assumed to be given ${ }^{2}$. In period $t$, the households who hold the capital stock of firm $i(0 \leq i \leq m)$ share the profit according to their capital contribution. The resulting payoff per unit of capital for them is:

$$
R_{i, t}=\frac{A_{i} K_{i, t}^{\alpha} L_{i, t}^{1-\alpha}-w_{t} L_{i, t}}{K_{i, t}} .
$$

We assume that households are atomistic and behave competitively. They take $R_{i, t}$ as given and invest their savings in firms providing the highest returns $R_{i, t}$.

Using these assumptions, the three steps of the game are the following.

1. At the beginning of period $t$, consumers allocate their savings $K_{t}$ among the different firms $i, 0 \leq i \leq m: K_{t}=K_{0, t}+\sum_{i=1}^{m} K_{i, t}$.

2. Their capital stock being installed, the $m$ non-competitive firms choose their labor demand $\left(L_{1, t}, . . L_{i, t}, \ldots L_{m, t}\right)$, such that

$$
\sum_{i=1}^{m} L_{i, t} \leq N_{t}
$$

3. There is an equilibrium on the labor market. This equilibrium is reached when the competitive labor demand of firm 0 is equal to the remaining quantity of labor after the decision of non-competitive firms, or

$$
w_{t}=A_{0}(1-\alpha) K_{0, t}^{\alpha}\left(N_{t}-\sum_{i=1}^{m} L_{i, t}\right)^{-\alpha} .
$$

As it is usual in Cournot-Walras competition, the strategies of non-competitive firms are constrained by (2) in such a way that an equilibrium exists. By assumption, firms $i=1, \ldots, m$ are the only strategic agents. Firm 0 and consumers behave competitively.

The game is solved by backward induction.

From step 3, the equilibrium condition on the labor market defines the equilibrium wage as a function of the demands of labor by non-competitive firms $L_{i, t}$, $i=1, \ldots, m$ :

$$
w_{t}=A_{0}(1-\alpha) K_{0, t}^{\alpha}\left(N_{t}-\sum_{i=1}^{m} L_{i, t}\right)^{-\alpha} \equiv \omega_{t}\left(L_{1, t}, \ldots, L_{m, t}\right) .
$$

\footnotetext{
${ }^{2}$ Households' savings behavior is described in section 3 .
} 
From step 2, each non-competitive firm $i$ maximizes its profit, taking into account the impact of its labor demand on the equilibrium wage:

$$
\max _{L_{i, t}} A_{i} K_{i, t}^{\alpha} L_{i, t}^{1-\alpha}-\omega_{t}\left(L_{1, t}, \ldots, L_{m, t}\right) L_{i, t}
$$

The optimal choice of $L_{i, t}$ is such that ${ }^{3}$ :

$$
(1-\alpha) A_{i} K_{i, t}^{\alpha} L_{i, t}^{-\alpha}-(1-\alpha) A_{0} K_{0, t}^{\alpha} L_{0, t}^{-\alpha}-(1-\alpha) \alpha A_{0} K_{0, t}^{\alpha} L_{i, t} L_{0, t}^{-\alpha-1}=0 .
$$

The third term of this equation stems from the non-competitive behavior.

Finally, from step 1, all capital returns must be equal:

$$
\forall i=1, \ldots, m, \frac{A_{i} K_{i, t}^{\alpha} L_{i, t}^{1-\alpha}-w_{t} L_{i, t}}{K_{i, t}}=\frac{A_{0} K_{0, t}^{\alpha} L_{0, t}^{1-\alpha}-w_{t} L_{0, t}}{K_{0, t}}=\alpha A_{0} K_{0, t}^{\alpha-1} L_{0, t}^{1-\alpha} .
$$

and the total capital stock is shared between all firms:

$$
K_{0, t}+\sum_{i=1}^{m} K_{i, t}=K_{t}
$$

In order to characterize the equilibrium of the game, it is convenient to introduce the following notations: $q_{i}=A_{i} / A_{0}, l_{i, t}=L_{i, t} / K_{i, t}, \lambda_{i, t}=l_{i, t} / l_{0, t}, p_{i, t}=K_{i, t} / K_{t}$ and $\tilde{p}_{i, t}=p_{i, t} / p_{0, t}$.

Equation (5) can be written:

$$
A_{i} l_{i, t}^{-\alpha}-A_{0} l_{0, t}^{-\alpha}-\alpha A_{0} \frac{K_{i, t}}{K_{0, t}} l_{i, t} l_{0, t}^{-\alpha-1}=0 .
$$

Dividing by $A_{0} l_{0, t}^{-\alpha}$ we obtain:

$$
q_{i} \lambda_{i, t}^{-\alpha}-1-\alpha \tilde{p}_{i, t} \lambda_{i, t}=0 .
$$

The equality of capital returns for each firm (6) defines the gross return on savings $R_{t}$ :

$$
R_{t} \equiv \alpha A_{0} l_{0, t}^{1-\alpha}=A_{i} l_{i, t}^{1-\alpha}-A_{0}(1-\alpha) l_{0, t}^{-\alpha} l_{i, t} .
$$

Dividing by $A_{0} l_{0, t}^{-\alpha}$ we obtain the equation:

$$
q_{i} \lambda_{i, t}^{1-\alpha}-(1-\alpha) \lambda_{i, t}=\alpha .
$$

Finally, the allocation of total capital on the different firms (7) leads to:

$$
p_{0, t}\left(1+\sum_{i=1}^{m} \tilde{p}_{i, t}\right)=1
$$

Equations (8), (10) and (11) allow to characterize the equilibrium of the game.

\footnotetext{
${ }^{3}$ The concavity of the profit function with respect to $L_{i, t}$ is satisfied, as the second derivative is $-\alpha(1-\alpha) A_{i} K_{i, t}^{\alpha} L_{i, t}^{-\alpha-1}-2 \alpha(1-\alpha) A_{0} K_{0, t}^{\alpha} L_{0, t}^{-\alpha-1}-(1-\alpha) \alpha(1+\alpha) A_{0} K_{0, t}^{\alpha} L_{i, t} L_{0, t}^{-\alpha-2}<0$.
} 


\subsection{Existence of the equilibrium between non-competitive firms}

In this section, we prove that our equilibrium concept leads to a unique equilibrium, and we describe its properties. We first remark that (8), (10) and (11) define a system of $2 m+1$ equations for $2 m+1$ variables, and that these equations do not depend on the period $t$. Consequently, $\forall i=1, \ldots, m, \lambda_{i, t}, \tilde{p}_{i, t}$ and $p_{0, t}$ are constant variables, that we will write further $\lambda_{i}, \tilde{p}_{i}$ and $p_{0}$.

From equation (8), we obtain that $\lambda_{i}$ is such that: $q_{i} \lambda_{i}^{-\alpha}>1$, or $\lambda_{i}<\left(q_{i}\right)^{1 / \alpha}$. Equation (10) has a unique solution $\lambda_{i}$ such that $\lambda_{i}<\left(q_{i}\right)^{1 / \alpha}$, and this solution defines $\lambda_{i}$ as a decreasing function of $q_{i}$. Moreover, as $q_{i} \lambda_{i}^{-\alpha}>1$, (10) implies that:

$$
\lambda_{i}-(1-\alpha) \lambda_{i}-\alpha<\lambda_{i} q_{i} \lambda_{i}^{-\alpha}-(1-\alpha) \lambda_{i}-\alpha=0 .
$$

Thus, $\lambda_{i}<1$. We have finally proved that all non-competitive firms have a smaller labor-capital ratio than the ratio in the competitive sector. The more productive a non-competitive firm is, the smaller its labor-capital ratio is, as $\lambda_{i}$ is a decreasing function of $q_{i}$. This property results from the higher market power of the more productive firms: they reduce their labor demand in order to decrease the equilibrium wage.

As for all $i=1, \ldots, m, \lambda_{i}$ is well-defined, we deduce from (8) the value of $\tilde{p}_{i}$, $\forall i=1, \ldots, m$ :

$$
\tilde{p}_{i}=\frac{q_{i} \lambda_{i}^{-\alpha}-1}{\alpha \lambda_{i}}
$$

which is an increasing function of $q_{i}$.

Finally $p_{0}$ is given by (11), and is a decreasing function of $q_{i}$. The share of capital held by firm $i p_{i}$ is given by:

$$
p_{i}=p_{0} \tilde{p}_{i}=\frac{\tilde{p}_{i}}{1+\sum_{j=1}^{m} \tilde{p}_{j}}
$$

which is an increasing function of $\tilde{p}_{i}$, and therefore an increasing function of $q_{i}$.

We have finally proved that, for each value of total capital, there exists a noncompetitive equilibrium in which all firms are productive. The higher the productivity of a firm is, the higher the share of capital that it employs at equilibrium is and the lower its labor-capital ratio will be. It is worth noting that, in an equilibrium with perfect competition, only the most productive firm would be active. With imperfect competition, the more productive firms strategically diminishes their labor demand to decrease the equilibrium wage. This behavior exerts a positive externality on less productive firms, which employ a higher labor-capital ratio, and which can attain the same level of capital productivity.

\subsection{Equilibrium prices}

At period $t, K_{t}$ being the total capital stock and $N_{t}$ the number of young people, it is possible to determine the equilibrium level of the wage $w_{t}$ and the gross interest 
rate $R_{t}$.

From the labor market equilibrium, we have:

$$
\begin{aligned}
& N_{t}=\sum_{i=0}^{m} L_{i, t}=\sum_{i=0}^{m} l_{i, t} p_{i} K_{t} \\
& N_{t}=l_{0, t} p_{0} K_{t}\left[1+\sum_{i=1}^{m} \lambda_{i} \tilde{p}_{i}\right]
\end{aligned}
$$

Finally, with $k_{t}=K_{t} / N_{t}$ denoting the ratio of capital per young agent, we obtain from (11):

$$
\begin{aligned}
l_{0, t}^{-1} & =k_{t} X \\
\text { with } X & =\frac{1+\sum_{i=1}^{m} \lambda_{i} \tilde{p}_{i}}{1+\sum_{i=1}^{m} \tilde{p}_{i}}
\end{aligned}
$$

In an economy with perfect competition, we would obtain $X=1$. In our economy with imperfect competition, we have $X<1$ as $\lambda_{i}<1$. For the competitive firm, the equilibrium labor-capital ratio $l_{0, t}$ is higher than its value for a perfectly competitive economy $1 / k_{t}$.

We can then deduce the values of the equilibrium wage (3) and gross interest rate $(9)$ :

$$
\begin{aligned}
& w_{t}=(1-\alpha) A_{0} l_{0, t}^{-\alpha}=(1-\alpha) A_{0} k_{t}^{\alpha} X^{\alpha} \\
& R_{t}=\alpha A_{0} l_{0, t}^{1-\alpha}=\alpha A_{0} k_{t}^{\alpha-1} X^{\alpha-1}
\end{aligned}
$$

In these two equations, the variable $X$ results from imperfect competition. As $X<1$, we see that imperfect competition tends to decrease the equilibrium wage, and to increase the gross interest rate, with respect to the case of perfect competition with the less productive technology.

\section{Households' behavior}

The production sector is part of a standard overlapping generations model with altruistic agents, based on Diamond (1965) and Barro (1974)-Weil (1987). Agents are living for two periods. The size of generation $t$ is $N_{t}$ and each agent has $(1+n)$ children. Parents care about their children's welfare. The utility of a generation $t$ agent, $V_{t}$, is given by

$$
\begin{aligned}
V_{t} & =U\left(c_{t}, d_{t+1}\right)+\gamma V_{t+1}, \quad 0<\gamma<1 \\
\text { with } U\left(c_{t}, d_{t+1}\right) & =(1-a) \ln \left(c_{t}\right)+a \ln \left(d_{t+1}\right)
\end{aligned}
$$

$c_{t}$ and $d_{t+1}$ respectively denote first period and second period consumptions. In their first period of life, individuals born in $t$ work and receive a wage $w_{t}$. In addition to their wage income, they receive a bequest $x_{t}$ from their parents. They consume $c_{t}$ 
and save an amount $s_{t}$. Gross returns on savings are equal to $R_{t+1}$ : at equilibrium, all firms provide the same return on capital. In their second period of life, people receive returns on savings and allocate net resources between consumption $d_{t+1}$ and bequests $x_{t+1}$ to their $(1+n)$ children. Thus

$$
\begin{aligned}
x_{t}+w_{t} & =c_{t}+s_{t}, \\
R_{t+1} s_{t} & =d_{t+1}+(1+n) x_{t+1} .
\end{aligned}
$$

Bequests must be non-negative :

$$
x_{t+1} \geq 0 .
$$

Maximizing the utility $V_{t}$ under the constraints (14), (15) and (16) leads to the standard first-order conditions

$$
\begin{gathered}
U_{c}^{\prime}\left(c_{t}, d_{t+1}\right)=R_{t+1} U_{d}^{\prime}\left(c_{t}, d_{t+1}\right), \\
-(1+n) U_{d}^{\prime}\left(c_{t}, d_{t+1}\right)+\gamma U_{c}^{\prime}\left(c_{t+1}, d_{t+2}\right) \leq 0 .
\end{gathered}
$$

The second condition holds with equality if $x_{t+1}>0$.

When bequests are constrained at all periods $\left(\forall t, x_{t}=0\right)$, equation (17) with a log-linear utility function leads to the simple saving function:

$$
s_{t}=a w_{t} .
$$

In the long run, the economy reaches a steady state that is called egoistic long run equilibrium.

When bequests are positive, it is well known that the economy converges towards the modified golden rule steady state:

$$
R=\frac{1+n}{\gamma}
$$

We call altruistic long run equilibrium this steady state.

Using a logarithmic instantaneous utility function, capital accumulation only depends on the equilibrium wage in an egoistic steady state, and on the gross return of capital in an altruistic steady state.

\section{The intertemporal long run equilibrium}

Two types of long run intertemporal equilibria may exist: an altruistic equilibrium with operative bequest $(x>0)$ and an egoistic equilibrium $(x=0)$.

At an altruistic long run equilibrium, the capital per young agent ratio $k_{t}$ converges towards a value $\bar{k}$, which is determined by (13) and by the modified golden rule (20): $R=\alpha A_{0} \bar{k}^{\alpha-1} X^{\alpha-1}=(1+n) / \gamma$, or:

$$
\bar{k}=\left(\frac{\alpha \gamma}{1+n}\right)^{\frac{1}{1-\alpha}} \frac{\left(A_{0}\right)^{\frac{1}{1-\alpha}}}{X}
$$


Along an egoistic long run equilibrium, the capital per young agent ratio $k_{t}$ converges toward a value $k^{*}$, which is determined by (12) and by the savings behavior of the agents $(19):(1+n) k^{*}=a w$, or:

$$
k^{*}=\left(\frac{(1-\alpha) a}{1+n}\right)^{\frac{1}{1-\alpha}}\left(A_{0}\right)^{\frac{1}{1-\alpha}}(X)^{\frac{\alpha}{1-\alpha}} .
$$

In both equations (21) and (22) the impact of imperfect competition on capital accumulation results from the variable $X<1$. Within an altruistic steady state, capital accumulation in the long run only depends on the return of capital. As imperfect competition tends to increase the gross interest rate, the capital per young agent ratio $\bar{k}$ is higher than under perfect competition. In contrast, within an egoistic steady state, capital accumulation in the long run only depends on savings that only depend on the equilibrium wage for a log-linear utility function. Thus, as imperfect competition tends to decrease the equilibrium wage, the capital per young agent ratio $k^{*}$ is smaller than under perfect competition.

The condition ensuring positive bequests in Weil (1987) remains the same in our framework. The steady state will be altruistic if $\bar{k}>k^{*}$, or $(1-\alpha) a X<\alpha \gamma$. As $X$ is smaller than 1 , this condition shows that the existence of an altruistic steady state is furthered by imperfect competition. This property was expected as imperfect competition tends to increase the return to capital .

\section{Technical progress and capital accumulation}

\subsection{Increasing productivity of a non-competitive firm}

We first study the impact of an increase of some $A_{i}, i \geq 1$. This is equivalent to consider that some $q_{i}$ increases, for $i \geq 1$. Such technical progress will affect capital accumulation through the variable $X$. It is worth noting that $X$ has an opposite effect on the two types of steady states, altruistic or egoistic. An increase of $X$ diminishes $\bar{k}$ and rises $k^{*}$. As a benchmark, we know that a technical progress in a competitive economy always increases capital accumulation, in both types of long run equilibria.

Proposition 1 it is possible to define some increasing function $\kappa(q)$ with $\kappa(1)=0$, such that, for each $q_{i}, i=1, \ldots, m$, the interval $K_{i}=\left(1, q_{i}+\kappa\left(q_{i}\right)\right)$ satisfies:

1. If for all $j \neq i, q_{j} \in K_{i}, \frac{\partial X}{\partial q_{i}}<0$. An increase of $q_{i}$ rises $\bar{k}$ and diminishes $k^{*}$.

2. If for all $j \neq i, q_{j} \notin K_{i}, \frac{\partial X}{\partial q_{i}}>0$. An increase of $q_{i}$ diminishes $\bar{k}$ and raises $k^{*}$.

Corollary $1 \quad$ 1. For $i=m$, as all $q_{j} \in K_{m}$, we have $\frac{\partial X}{\partial q_{m}}<0$. An increase of $q_{m}$ raises $\bar{k}$ and diminishes $k^{*}$.

2. $q_{1}$ is the only variable that can satisfy point 2 of proposition (1). Particularly, if $q_{1}$ is sufficiently small, ( $q_{1}$ tends toward 1 ), $\frac{\partial X}{\partial q_{1}}>0$. An increase of $q_{1}$ diminishes $\bar{k}$ and raises $k^{*}$. 
These results show that a technical progress can have various effects on capital accumulation. The first case is obtained when all firms $j$ have a productivity parameter $q_{j}$ close to $q_{i}$ (close in the sense that $q_{j} \in\left(1, q_{i}+\kappa\left(q_{i}\right)\right)$ ). The second case is obtained when $q_{1}$ is sufficiently small with respect to $q_{2}, q_{3}, \ldots q_{m}$. Therefore, the impact of a technical progress on capital accumulation depends on two components: on the initial productivity of the firm experiencing a technical progress with respect to other firms, and on the type of long-run equilibrium - egoistic or altruistic.

This latter component can be understood, having in mind that the rise of productivity of a non-competitive firm has opposite effects on factors remuneration at equilibrium: if the equilibrium wage increases, the rate of return decreases and vice versa. Therefore, if capital accumulation increases for an egoistic steady state, it will decrease for an altruistic one and conversely.

The former component can be explained, as an increase of one firm's productivity leads to two opposite effects. First, the firm reduces the quantity of labor used per unit of capital. This effect tends to decrease the equilibrium value of the wage and to increase the capital return. Second, since all capital returns are equal at equilibrium, the firm holds a higher share of the total capital of the economy. If the firm that benefits from this productivity increase is the most productive $(i=m)$, this second effect acts in the same sense as the first one. Therefore, the equilibrium wage decreases and the capital return increases. But, if the firm that benefits from this productivity increase is not the most productive one $(i<m)$, the second effect acts in opposite direction to the first one, and the global effect is ambiguous. Particularly, it is proved that for the less productive non-competitive firm, it is possible that a rise in its productivity increases the equilibrium wage and decreases the capital return.

\subsection{Increasing productivity in the competitive sector}

We study the impact of an increase of $A_{0}$ on both types of stationary equilibrium $\bar{k}$ and $k^{*}$. From (21) and (22), $A_{0}$ has a direct effect and an indirect effect via the variable $X$. Indeed, increasing $A_{0}$ implies a decrease for all $q_{i}, i \geq 1$.

The following proposition shows that an increase of $A_{0}$ can have various effects on capital accumulation.

Proposition 2 1. When $q_{m} \rightarrow+\infty, \frac{d \ln k^{*}}{d A_{0}} \rightarrow \frac{1}{A_{0}(1-\alpha)}$ and $\frac{d \ln \bar{k}}{d A_{0}} \rightarrow 0$.

2. When $q_{1} \rightarrow 1, \frac{d \ln k^{*}}{d A_{0}} \rightarrow-\infty$ and $\frac{d \ln \bar{k}}{d A_{0}} \rightarrow+\infty$.

3. When $\forall i \geq 1, q_{i}=q, \frac{d \ln k^{*}}{d A_{0}}>0$ and $\frac{d \ln \bar{k}}{d A_{0}}<0$. By continuity, these properties hold when the $q_{i}, i \geq 1$, are sufficiently close together.

These results show that when the total factor productivities of non-competitive firms are close, an increase of $A_{0}$ tends to increase capital accumulation in an egoistic steady state, and to decrease capital accumulation in an altruistic steady state. This effect results from the increase of the wage and the decrease of the capital return. In contrast, the results may be reversed when the total factor productivities of noncompetitive firms are distant. 
The direct effect of an increase of the productivity in the non-competitive sector is a rise of both wage and capital returns. But an indirect effect stems from the fall of the relative productivity of all non-competitive firms, which modify their market power. If non-competitive firms have close productivities (case 3), the productivity increase in the competitive sector implies a fall in the market power of all non-competitive firms, which causes an increase of wages and a decrease of capital returns. If non-competitive firms have distant productivities (cases 1 and 2), the productivity increase in the competitive sector redistributes market power in favor of the most productive firms, and to the detriment of the less productive ones. The resulting effect on capital accumulation may be reversed with respect to case 3 .

\subsection{Growth with random innovations}

In this last section, we provide a simple extension of the model, introducing random innovations. We assume that at each period, with a probability $\pi$, one firm receives an innovation (and with probability $1-\pi$, no innovation occurs in the whole economy). This innovation increases the productivity by a factor $\delta>1$, with respect to the common technology. Finally, each innovator has an exclusive use of its new technology during only one period. After that period, there is free access to this technology.

From the preceding assumptions, at each period $t$, either the economy is purely competitive and the common productivity is $A_{0, t}$, or one non-competitive firm has a productivity level $A_{1, t}=\delta A_{0, t}$ while the other firms are competitive with the common productivity $A_{0, t}$.

We only consider the egoistic equilibrium in this part, as we want to analyze the dynamics of capital accumulation. The dynamics of $k_{t}$ with random innovations can be written:

$$
(1+n) k_{t+1}=a(1-\alpha) A_{0, t} k_{t}^{\alpha} X_{t}^{\alpha} .
$$

With probability $\pi$ (arrival of an innovation in $t$ ):

$$
\begin{aligned}
X_{t} & =\frac{x}{1+x(x-1)} \\
\text { with } x & >1 \text { the solution of } \delta=\alpha x^{1-\alpha}+(1-\alpha) x^{-\alpha} \\
A_{0, t+1} & =\delta A_{0, t}
\end{aligned}
$$

With probability $1-\pi$ (no innovation in $t)$ :

$$
\begin{aligned}
X_{t} & =1 \\
A_{0, t+1} & =A_{0, t}
\end{aligned}
$$

As $x>1$, we have $\frac{x}{1+x(x-1)}<1$. The arrival of an innovation has a negative short run effect on the growth rate, because imperfect competition decreases the equilibrium wage. But, after one period, the effect is positive as the technology is available for the competitive sector. The greater the size of the innovation $\delta$ is, the larger both short run and long run effects will be. 
This simple example shows that a technical progress can have two paradoxical effects in the short run: first, it can cause a fall in capital accumulation; second, it can increase the share of GDP devoted to capital income and decrease the share devoted to labor income. These two effects result from the non-competitive behavior of innovating firms.

\section{Conclusion}

This paper has studied how long run growth can be affected by strategic behavior of firms in the labor market. The main results show the paradoxical effects associated with imperfect competition: a technical progress may decrease capital accumulation if it leads to distortions due to imperfect competition.

Our work could lead to further developments, mostly in endogenizing the technical progress by an explicit innovative activity of the firms. Growth models in which innovation is the source of growth are natural frameworks to develop our analysis, since they make endogenous productivity differences of firms.

\section{References}

Barro, R. J. (1974), "Are government bonds net wealth ?," Journal of Political Economy 82, 379-402.

Belan, P., P. Michel, and B. Wigniolle (2002), "Pension funds and capital accumulation," Economics Bulletin 4, 1-8.

Belan, P., P. Michel, and B. Wigniolle (2005), "Does imperfect competition foster capital accumulation in a developing economy?," Research in Economics 59, 189208.

Becker, R. A. (2003), " Stationary strategic Ramsey equilibrium," mimeo, Department of Economics, Indiana University.

Bhaskar, V., A. Manning, and T. To (2002), "Oligopsony and monopsonistic competition in labor markets," Journal of Economic Perspectives 16, 155-174.

Codognato, G., and J. J. Gabszewicz (1993), "Cournot-Walras equilibria in markets with a continuum of traders," Economic Theory 3, 453-464.

Diamond, P. (1965), "National debt in a neoclassical growth model," American Economic Review 55, 1126-1150.

Gabszewicz, J. J., and J. P.Vial (1972), "Oligopoly à la Cournot in general equilibrium analysis," Journal of Economic Theory 49, 10-32.

d'Onofrio, B., and B. Wigniolle (2006), "Imperfect competition, technical progress and capital accumulation," Cahiers de la MSE 2006.46, Université de Paris 1.

Sorger, G. (2002), "On the long-run distribution of capital in the Ramsey model," Journal of Economic Theory 105, 226-243.

Weil, P. (1987), "'Love thy children': reflections on the Barro debt neutrality theorem," Journal of Monetary Economics 19, 379-391. 